Article

\title{
Preparedness and Multiagency Collaboration-Lessons Learned from a Case Study in the Norwegian Armed Forces
}

\author{
Trygve J. Steiro ${ }^{1, *}$ and Glenn-Egil Torgersen ${ }^{2}$ \\ 1 Department of Teacher Education, Norwegian University of Science and Technology, \\ 7012 Trondheim, Norway \\ 2 Department of Business, History and Social Sciences, USN School of Business, University of South-Eastern \\ Norway, Campus Vestfold, 3184 Borre, Norway; Glenn-Egil.Torgersen@usn.no \\ * Correspondence: trygve.j.steiro@ntnu.no
}

Received: 10 August 2020; Accepted: 1 September 2020; Published: 4 September 2020

\begin{abstract}
The objective of this study is to investigate the structure for learning and the learning outcomes from a paper exercise based on multiagency collaboration, and point to potential benefits for crisis leadership and management in civil organizations. The current study was conducted by participant observation in one exercise and a questionnaire was handed out in the following exercise to measure outcomes. Social interaction and concurrent learning are used as the theoretical foundation in the current study. The exercise can be used as an input for multiagency collaboration when linked to the strategic and operative context. The Norwegian Armed Forces operate from a leadership perspective of intention-based leadership. The organization has also developed a pedagogical platform that guides learning activities. In a complex world, we aim at finding training areas that can prepare the cadets for scenarios that also heavily involve the unforeseen. Improvisation is seen as important for military leaders and the exercise provides a sound arena for this purpose. We have seen that even for a table exercise, important lessons can be learned. The current study makes suggestions as well as improvements that could be performed based on the lessons learned for both the Norwegian Armed Forces as well as for other organizations that find the experiences interesting. The article identified five management principles for interaction under unforeseen conditions: (1) develop a pedagogical view for the organization, (2) facilitate and train using processes for complementary process development, (3) develop precise and common language, (4) train the organization in concurrent learning, (5) develop tolerance and mutual respect.
\end{abstract}

Keywords: interaction; concurrent learning; exercise; unforeseen

\section{Introduction}

An air force is termed as a high-risk organization within the taxonomy of Charles Perrow [1]. It has been argued that military operations and especially sharp operations can be described as dynamic, turbulent and competitive [2]. Norway, like many other nations, has applied "mission command" that aims to reduce the gap between plans and the actual chaos of war. Today's officers must be capable of autonomous decision-making in both rapidly changing and ambiguous situations. Officers will even, early in their career, need a capacity for divergent thinking and problem-solving skills. Military officers can be put in command and control situations depending on their skills and experience, but also ones demanding improvisation [3]. Clausewitz (1832/1976, p. 119) [4] termed "friction" as a discrepancy between the plan and what was occurring on the battlefield [5,6]. Considering this, the United Nations Air Power Operation (UNAPO) is a fictional operation run as a paper exercise. The end of the exercise does not seek a "fixed" solution or "the school's solution" as it is pointed out in the start of the exercise. 
The cadets are presented with a mission and the intention of the commander. The commander is typically an operative officer. Then the cadets representing the different nations pull back to develop a plan and present it in a plenary. The following tasks are performed in the exercise:

- Setting up an air defence involving different nations

- A planned air assault on a strategic target with the presentation of different solutions by the different nations with suggested efforts from the other nations

- An opportunity to strike an enemy target that is time-sensitive

- A combat search and rescue operation of a fighter pilot who has been forced to bail out over enemy territory

- Moving a large number of refugees from an insecure to a safe location.

The Royal Norwegian Air Force Academy (RNoAFA) is a branch of the Norwegian Defence College responsible for educating officers for the different branches of the Royal Norwegian Air Force. One of the key aspects is mission command and to be educated in, understand, and know how to use air power with its strengths and limitations. The cadets come from different branches of the Air Force and understanding the different concepts of the Air Force is important. It is also important to understand the interplay with other air forces as well for the understanding of air power. The cadets will serve as officers in positions both nationally and internationally as officers operating on the line or as staff officers. In 2011, the Royal Norwegian Air Force participated in the air campaign over Libya and played a very active role in the operation. This has called for a focus on the use of air power in an international context and for the scaffolding of the experiences obtained in the operation.

The objective of this study is to investigate the structure for learning and the learning outcomes of such an exercise, report on experiences, and point to factors that might be relevant for crisis management. The theoretical foundation the article is based on is learning leadership, mission-based leadership, social interaction and concurrent learning. The current study might be a case example for contributing to the fight against pandemics, in particular COVID-19.

\section{Theoretical Framework}

The theoretical section is divided into five sections:

- $\quad$ The leadership context

- Learning leadership

- Mission-based leadership

- Social interaction ("samhandling")

- Concurrent learning.

\subsection{The Leadership Context}

Northouse [7] writes that leadership must be understood in the context in which one operates. Northouse [7] divides leadership competence into three parts:

1. Substantial competence such as production and technology and industry

2. Competence in people and social relationships

3. The ability for abstraction.

A central aspect of leadership in the Armed Forces of Norway and allied nations is mission command. Mission command or "intention-based" leadership as it is termed in Norway is based on the commander given the objective or intent and the "why". The operative level must within the framework find out the "how". This implies decentralized decisions and task solving is based on the practical judgement of the commanding officer at the sharp end [8]. Information regarding the why is very important to determine $[9,10]$. Hence, the commander would form the "intent" of the mission, thus providing a framework and guidance. Within the framework the operative level is also able to 
improvise on the battlefield to fulfil the mission, but in addition also exploit opportunities that occur from the friction in the war $[11,12]$.

\subsection{Learning Leadership}

A central aspect of the RNoAFA is educating leaders that will operate within the context of air power. Learning leadership means that working and learning is as much a way of life at the RNoAFA for educating leaders, as it is among the staff [13]. The RNoAFA operates as a community of interdisciplinary practitioners with diverse expertise that must be aligned, and therefore a key characteristic is that each is valued for their contribution irrespective of rank and seniority. There is a focus on embracing diversity and celebrating heterogeneity [13]. This in everyday practice means that critiquing is a way of living and working. The staff at RNoAFA reinforce ongoing learning individually and collectively [13]. In "Global Competence in an Inclusive World" [14], the OECD writes: "Global competence includes the acquisition of in-depth knowledge and understanding of global and intercultural issues, the ability to learn from and live with people from different backgrounds, and the attitudes and values necessary to interact respectfully with others" (OECD, 2016: 1) [14].

\subsection{Mission-Based Leadership}

The purpose of developing "mission-based leadership" in the Armed Forces is to better deal with uncertainty and to meet an unknown future with greater agility. This implies that education must include creating solutions; maintaining self-awareness and situational awareness and forming a comprehensive understanding, as well as exercising independent decisions and translating plans and intentions into action. With this, the Armed Forces have chosen a decentralized command system, where the operative level will be able to act independently and flexibly and independently within the commander's intention [9,10]. This requires leadership that emphasizes cooperative and relational skills to create common understanding as to why it should be done (commitment) and how to do it (interaction) [13]. The benefits of the UNAPO exercise should therefore be seen in light of mission command.

\subsection{Social Interaction (Samhandling)}

Herberg, Torgersen and Rundmo (2019) have identified social interaction and concurrent learning (CL) as key factors for meeting the unforeseen in a study conducted among military personnel [15]. Torgersen and Steiro defined "samhandling" as: "Samhandling is an open and mutual communication and development between participants, who develop skills and complement each other in terms of expertise, either directly, face-to-face, or mediated by technology or by hand power. It involves working towards common goals. The relationship between participants at any given time relies on trust, involvement, rationality and industry knowledge" [16]. Samhandling is not only reserved for senior management and it typically takes place in production and common processes in which people work and act together. This action is based on shared and exchanged expertise which is often extensive, specialized, and used in a complementary manner [16,17]. Miles and Watkins [18] support the notion that interaction is more than the sum of its parts and focus on complementary competencies.

\subsection{Concurrent Learning}

As we saw, Herberg, Torgersen and Rundmo (2019) have highlighted CL in military organizations. CL can be defined as: "A deliberate and continuously functional and interacting learning process among actors that occurs simultaneously with the interaction" [17] (p. 335). Learning in this form does not merely take place by chance. CL is both intentional and purposeful. Stakeholders or participants need to be aware of this process and focus on the relationship between one's own and others' expertise and diversity and focus on the complementary. Samhandling and CL represent a mindset to tackle the challenges of flexible organizations [16]. Therefore, the utilization of complementary expertise and CL are important strategic measures for the efficient development of flexible features for organizations [17]. 
This is also highlighted in Torgersen and Steiro [19]. The distinction between interaction, collaboration and teamwork is that interaction is an extra emphasis and awareness of the complementary:

- with arrangements for the exchange and utilization of the participants' different competence, experience, background and culture,

- and channeling (coordination) of this into the work towards a common goal in a work or meeting process.

- In collaboration, common understanding is built and developed with different competence and understanding through concurrent learning [19].

They refer to the corresponding exchange of a number of knowledge structures combined with developing the ability to interact, and teach as an event occurs, as CL, and which is defined as: "A deliberate and continuously functional and interacting learning process among actors that occurs simultaneously with the interaction" [18] (p. 253).

In military contexts, CL can be compared to the principle of "train as you fight" $[20,21]$ as we see it, but CL has a more systematic and combined learning content, which also includes the debrief phase. Therefore, CL competence will be important to develop in all types of emergency environments, both civilian and military. Heifetz, Grashow and Linsky [22] think of leadership in terms of "putting a hand on a thermostat". They argue that if the heat is too low, people will not make a decision. If the heat is too high, people might panic. This implies, as we see it, the need for CL. This could be assured by, for instance, the extensive use of debriefing [23].

\section{The Context of the Exercise}

The Air Force Academy of Norway has invested a great deal of resources in the education of cadets. The curricula are based on a blend of theory, practice and reflection [24]. The challenge is to ensure an appropriate mix of these factors and set them in a relevant context. The exercise is inspired by a human rights concept of the Air Force Academy in Italy, where an air operation is simulated and cadets from different nations are challenged in San Remo to provide human rights answers to commanders in an air operation. The RNoAFA was inspired by the concept and has created its own exercise for cadets in Norway. The Norwegian version is based on a joint international air operation to protect a group of people from attack in one nation. The exercise is played out under a United Nations umbrella. However, points made in the exercise and expressed in this article must not be seen as the opinion of the United Nations. It is an exercise played out where the nations are labeled "Blue", "Black", and "Green" etc. Each nation is assigned air power capacities with individual descriptions. The first author played the role of nation "Green" with eight F-16 fighters, one Hercules air transport and a platoon of Special Operation Forces (SOF), meaning a medium-large player in the field. In addition, they were given a mandate of being offensive and were known to follow the line of the lead nation "Blue". Both "Green" and "Blue" nations had few caveats (restrictions mandated by the respectively politicians). The exercise demanded the cadets operate on a table (or paper-based exercise) in a complex environment, demanding heterogeneous competence and involving ethical consideration. The exercise can therefore be perceived as an example of Bennis and O'Toole's [25] suggestion for management training. The airpower exercise lasts for five full days and ends in with a wrap-up and lessons learned in a session on day five. Antonacopoulou and Sheaffer's [26] account for why organizations and individuals fail to learn from failure and repeat the same mistakes again by embedding crisis in learning is a mode of learning they define as "learning in crisis" [26] (p. 4). This means that the UNAPO exercises should not be about finding the right solutions, but rather learning from experience and from mistakes.

\section{Methods and Materials}

The method applied was participant observation of the exercise. The first author participated in the exercise in 2015 as a participant playing the Green nation, as mentioned earlier. At that time 
research was not thought of as just being part of a learning area with the staff and cadets. The first author was working as an associate professor at RNoAFA, but with no participation in the planning and the execution of the exercise, only as a participant. After participating in the exercise, the first author discussed the experience with the second author and both agreed that the exercise would be of interest to explore in greater detail. The idea of conducting research was further discussed with the officer responsible for the exercise. He was positive and allowed us to conduct research. Having been part of the exercise was a major advantage for developing a questionnaire for conducting research the next time the exercise was performed with a new group of cadets in December 2015. It was decided to hand out the questionnaire to the cadets on the morning of day five (the last day of the exercise) before the "hot wash-up" and debrief of the exercise. "Hot wash-up" involves the immediate responses from the participants taking part in the exercise. This is unfiltered and can be seen as a "brainstorming" session. Next, a structural debrief is performed. By providing the questionnaire before these processes, the research material was not influenced by the processes. All 25 cadets were asked to fill out the questionnaire and all 25 gave their consent for the second exercise in 2015. Of the 25 cadets, there were five women and 20 men ranging from 22 to 32 years with a mean of 25 years. The questionnaire was taken directly from Berlin and Carlström [27] (p. 32), focusing on themes regarding:

- Collaboration

- $\quad$ Learning

- Usefulness

In addition, some questions (items) from Torgersen and Steiros's 10-factor questionnaire for relational indicators for effective social interaction in organizations [16] were also included. The questions asked were:

- $\quad$ Are all actors in the exercise treated with the same respect?

- Involvement awareness. Are all actors in the exercise equally willing to contribute actively?

- Complementary competence (complement each other with unique competence). Did all actors contribute with their industry-specific expertise?

- Did the exercise help to develop a common understanding of language?

- Through the exercise, have I gained more confidence in the other actors?

All questions in the battery $(n=23)$ were based on a 5-point Likert scale from strongly disagree to strongly agree. In addition, we added a category "I do not know/no view" because we wanted this as a further option. No cadets used this category for any questions, implying that all questions could be seen as relevant.

The study will present the exercise in detail and assess the learning outcome. It will link the learning outcome to relevant operations. It will also argue that such an exercise plays a valuable role in meeting demands for training managers for performing of complex assignments in organizations [25]. The study will not only document responses but also investigate means for the improvement of the structure of the exercise and the learning output and potential benefits for other organizations.

\section{Results}

The questionnaire revealed several interesting findings. Based on the response, the following table can be presented. The questionnaire was based on a 5-item Likert scale. However, we have merged disagree/strongly disagree and agree/strongly agree in order to make it more readable and to ensure a better overview. The results are presented in Table 1 . 
Table 1. Participants' report on outcome of the exercise. $(n=25)$.

\begin{tabular}{lccc}
\hline \multicolumn{1}{c}{ Questions } & $\begin{array}{c}\text { Disagree/Strongly } \\
\text { Disagree }\end{array}$ & $\begin{array}{c}\text { Middle } \\
\text { Value }\end{array}$ & Agree/Strongly Agree \\
\hline Opportunities to improvise & $8 \%$ & $8 \%$ & $84 \%$ \\
between organizations & $4 \%$ & $12 \%$ & $84 \%$ \\
My points of view were acknowledged & - & $4 \%$ & $96 \%$ \\
I learned new things during the exercise & $4 \%$ & $28 \%$ & $64 \%$ \\
It is useful for real-life activities & $16 \%$ & $40 \%$ & $44 \%$ \\
Impact on my daily work & $16 \%$ & $20 \%$ & $64 \%$ \\
All actors treated with the same respect & $12 \%$ & $16 \%$ & $72 \%$ \\
Complementary competence was used & $16 \%$ & $40 \%$ & $44 \%$ \\
More trust during the exercise & & & \\
\hline
\end{tabular}

The questionnaire reveals that the exercise produces several important outcomes. However, the number of respondents was low, so we have used it for creating an overall impression. It can be argued based on the response to the questionnaire that the exercise strengthens the collaboration within the group. However, this is reported and is not viewed in practice. Therefore, it is fair that the respondents expect a strengthening rather than actually experiencing a strengthening. It was also reported that room for discussions during and after the exercise is needed and might be structured for CL and social interaction. This has been stressed as very important in order to strengthen collaboration [16]. Debriefing is important in order to strengthen CL. The exercise, as noted earlier, consisted of different types of operations which were concluded before moving to the next operation. We also found support from the cadets' point of view that the exercise provides opportunities for improvisation and trying out different strategies regarding collaboration among the participating organizations. In this regard, the different nations [3] focused on the importance of military leaders' ability to improvise. Another finding is that they reported that they learned about collaborating organizations' priorities. This is a reported outcome but still might assume strengthening the knowledge regarding what decisions are made, but to a lesser degree on how the actual priorities are decided or negotiated in real life. Regarding elements that are not so positive, there are some aspects that stand out, despite an overall positive impression. The cadets were divided down the middle on whether they perceived the exercise as useful in their daily life. This might imply that different cadets or branches of the Royal Norwegian Air Force are better covered. Air operations are complex and covering several scenarios in just four days could be too ambitious. One must ask, how much did they learn in detail from such an exercise? More instructions regarding collaboration could be provided. Having said that, the exercise seems to be most heavily focused on air power planning and decision making. At the same time, it is hard to put too many expectations into an exercise. But there is a potential as we see it to strengthen this part. This could be achieved by having a "time out" focusing on this issue and asking the cadets to write down their reflections regarding collaboration issues given the use of a "Blue Book". The academy uses a so-called Blue Book in which to write down reflections [16]. We did not observe the use of this Blue Book when the first author was part of the exercise. In the exercise, an air raid resulted in severe collateral damage so the success of the mission was, to say the least, very questionable. However, no further discussion was raised. There could have been a possibility to raise questions. But the participants, including the first author, did not raise any questions, nor was it encouraged. We think that what you focus upon is important for addressing different issues. We also observed that the cadets did not report increased trust in each other. This might, however, imply that trust was high before the start of the exercise. An alternative might be that the content of the exercise does not go into any real depth. The case of collateral damage was one where participants were vulnerable. Who is to blame? What should be done to mitigate the damage? A third assumption might be that this was a paper exercise and that, by playing different nations, the cadets were playing roles, rather than truly giving themselves. Being in a more naturalistic and hostile environment, say crossing the mountains as a team in the winter, combating stormy weather, fatigue, and stress would be better suited for building 
trust. This curriculum was also covered earlier at the RNoAFA. This can be viewed as a negative aspect. In addition, the cadets were together almost every day following a tight schedule and curricula and at the time of the exercise half the class had been together for 1.5 years. All of them were together for half a year (the last ones to enter were experienced officers that had earlier gone through the the first year, which is mandatory before going for pilot training in the USA). It can be argued that, for this group, trust was not strengthened. It might already have been at a very high level [27]. The exercise focuses on a strategic planning team that bring to getter personnel from different organizations or different departments in large organizations. So, the question is also relevant for the cadets. They also reported less relevance to daily activity. That could be interpreted as meaning that this exercise is on a high level that is said to be relevant. There might be a greater complexity demanding interdisciplinary collaboration and involving ethical dilemmas that might be less visible in the day-to-day activities at the academy [27]. It stresses the importance of training students in complex scenarios demanding interdisciplinary collaboration and ethical dilemmas. Perhaps it could be argued that more of the curricula at the academy should be linked to the exercise? This means that more resources should be used in order to foster more learning from the exercise and that teachers and facilitators should be used to scaffold the exercise and later use it as examples in the curricula. A natural development from the UNAPO exercise is that the cadets are put in the role of the commander and writing the intention of missions. In the UNAPO exercise, all cadets play the same role as executors, not the mission commander. Having one group acting as the mission command team could challenge the cadets even more.

\section{The Norwegian Defence Pedagogical View (FPG)}

The Norwegian Armed Forces has a comprehensive strategic curriculum with regards to the pedagogical approach and overall learning objectives for learning activity. This is the Armed Forces' pedagogical basic view [27]. This plan focuses consistently on collaboration, development of creativity and problem solving. In addition, emphasis is placed on teaching and exercise methods, where no work is performed towards a defined conclusion, but instead situation-oriented solutions adapted to the challenges and conditions that exist. Competence is important for dealing with unforeseen events. In the preface of the document, it is stated, among other things:

“... The military profession presupposes the ability to mobilize knowledge, attitudes and skills in both familiar, new and unexpected circumstances in relation to persons with different backgrounds, to equipment and new technology. This makes great demands on the learning activity that is taking place in the Armed Forces in relation to education and training. There are also demands on the individual's ability learn, cooperate, evaluate and adapt to different situations.

The changes in the organization and the tasks of the Defense demand inspection of and development of the pedagogical activity. The pedagogical execution of the Defense's branches of education and courses will be an important success criterion to succeed in developing a quality oriented, effective, flexible and alteration willing Defense.

The Defense already has a good and well-developed educational system, but there may be aspects that have to be improved to meet new challenges. The basic pedagogical view (FPG) of the Defense shall make sure of a common platform for teaching, both internally and what is bought externally. FPG shall be the guideline for all pedagogical activities within the Defense. FPG is based upon the basic values of the Defense, and must also be seen in relation to basic military leadership (GML) the common operative doctrine (FFOD) of the Defense and the personnel manual (FPH). These together are an important force to produce effective learning ... " ([27], preface).

Of course, training is also based on basic fixed procedures and solutions, but the concept of learning and pedagogy has several dimensions and is more holistic than that which has traditionally been seen in military organizations (before FPG was introduced). In itself, the development and 
implementation of an organization's pedagogical philosophy will be a feature to be determined for the competence development in an organization. Therefore, it is somewhat surprising that several large civilian companies and institutions, and other countries' military organizational zones, do not already have this. This is an important lesson, and we believe that we can strongly state that a well-functioning FPG in the organization is crucial for successful competence development. Without FPG, strategic management and training are built without a foundation.

\section{The Lessons Learned: Overall Discussions and Implications}

The cadets reported overall positive experiences regarding collaboration and learning. They reported less favorable ones regarding the usefulness in daily activities and trust. However, the number of reports was small, which should also be a consideration. Further distribution of the questionnaire is recommended in order to gather more data and compare the different classes of cadets and thereby create CL in order to strengthen the pedagogical outcome, as pointed out in FPG [27]. We will also advise distributing the questionnaire during the exercise to facilitate more CL. If teamwork was essential and the cadets reported low scores on this issue, more emphasis on this could be introduced during the exercise. In a complex world we aim to find training areas that can prepare the cadets for scenarios that also heavily involve the unforeseen. Improvisation is seen as important for military leaders and the exercise provides a sound arena for this purpose. However, again, it is necessary to ask how they will use improvisation after the exercise. We have seen that, even for a table exercise, important lessons can be learned. The point is not having live planes, but rather solving tasks and garnering feedback and learning. The overall experience is reported to be very positive. In the current study, only the cadets filled out the questionnaire. For further exercises, the instructors might also fill out a questionnaire for creating a more dynamic learning environment and enabling more CL, thereby fostering CL between teachers/facilitators and cadets. It can also be supported by semi-structured interviews by researchers not playing a part of the planning and execution of the exercise. Another point to address is that, in another study [28], it was pointed out that some instructors focus only on the product and not on the process. The students, however, favored instructors focusing on both the process and product [28]. Further development of the UNAPO exercise would benefit from addressing both the product and the processes. Another factor is that CL will demand that instructors and cadets need to stop, reflect and adjust when under way, as [22] when thinking of leadership as putting a hand on the thermostat. The idea of the hand on the thermostat, which either speeds up the pace of the exercise or pauses it to reflect on something emergent, could be a fruitful path to take. If the exercise is perceived either by cadets or teachers/ facilitators as going slow, the "heat" could be turned up to create more stress, or strengthen the complexity, or to reveal an ethical dilemma that could be further explored [25]. In addition, it will be necessary for the organization to have developed a unified pedagogical philosophy, which can form the foundation for strategic management, training and renewal. Not least, this applies to building the right skills and a flexible and adaptable mindset to deal with unforeseen events during situations, including pandemics. The UNAPO exercise is developed within an air power context. We have seen that context is important for the leadership of organizations [7], but we think there are some generic lessons that could be addressed. A paper exercise allows for complex scenarios to be played out. We also know from scenario planning that it contributes to strengthening the relations between the participating actors [29]. In this respect the current study provides an example of the seminal work of De Geus (1988) [29]. Regarding more recent research, we think the current study should be seen in light of the work of Herberg et al. (2019) [15], understanding $\mathrm{CL}$ and social interaction. The current study might provide a concrete example to facilitate such processes. The current study might be a case example for contributing to the fight against pandemics, in particular COVID-19, especially in relation to extracting experiences and research finding from military pedagogy and psychology, with implications for handling competence and knowledge strategies to provide infection control [22]. 


\section{Conclusions: Five Crisis Management Principles}

All in all, in this study we have identified five crisis management principles for developing competence for interaction under unforeseen conditions and these principles are identified as:

(1) Develop a pedagogical view for the organization

(2) Facilitate and train for complementary competence process development

(3) Develop precise and common language

(4) Train the organization in concurrent learning

(5) Develop tolerance and mutual respect

These principles should permeate strategic contingency plans and practical crisis management, to ensure the development of the necessary expertise for interaction under risk and unpredictable conditions. The principles can also serve as quality indicators in evaluation and improvement processes in the organization. However, it is necessary for the individual organization to adapt and concretize the principles to its specific activities and tasks.

Author Contributions: The first author (T.J.S.) has planned, executed the data collection and analysed the results. The second author (G.-E.T.) contributed in the planning of the study, analysed the results, deduced conclusions, and contributed in the writing process. All authors have read and agreed to the published version of the manuscript.

Funding: This research received no external funding.

Conflicts of Interest: The authors declare no conflict of interest.

\section{References}

1. Perrow, C. Normal Accidents: Living with High-Risk Technologies; Basic Books: New York, NY, USA, 1999.

2. Visser, M. Teaching giants to learn: Lessons from army learning in World War II. Learn. Organ. 2017, 24, 159-168. [CrossRef]

3. Brady, M. Improvisation versus rigid command and control at Stalingrad. J. Manag. Hist. 2011, 17, $27-49$. [CrossRef]

4. Clausewitz, C.V. On War; The Complete Edition; Princeton University Press: Princeton, NJ, USA, 1976; Originally published in 1832.

5. Gross, G.P. The Myth and Reality of German Warfare: Operational Thinking from Moltke the Elder to Heusinger; University Press of KY: Lexington, KY, USA, 2016.

6. Vandergriff, D.E. From Swift to Swiss: Tactical decision games and their place in military education and performance improvement. Perform. Improv. 2006, 45, 30-39. [CrossRef]

7. Northouse, P.G. Leadership: Theory and Practice; Sage Publication: Thousand Oaks, CA, USA, 2018.

8. Antonacopoulou, E.P.; Moldjord, C.; Steiro, T.J.; Stokkeland, C. The New Learning Organisation: PART I-Institutional Reflexivity, High Agility Organising and Learning Leadership. Learn. Organ. 2019, 26, 304-318. [CrossRef]

9. Chief of Defense. Chief of Defense Basic View on Leadership; Forsvarsstaben: Oslo, Norway, 2012; pp. 6-7.

10. Norwegian Defense University College. Armed Forces Joint Doctrine; Forsvarssjefen: Oslo, Norway, 2014; p. 166.

11. Murray, W. Military Adaptation in War: With Fear of Change; Cambridge University Press: New York, NY, USA, 2011.

12. Shamir, E. Transforming Command: The Pursuit of Mission Command in the US, British and Israeli Armies; Stanford University Press: Stanford, CA, USA, 2011.

13. Antonacopoulou, E.P.; Moldjord, C.; Steiro, T.J.; Stokkeland, C. The New Learning Organisation: PART II-Lessons from the Royal Norwegian Air Force Academy. Learn. Organ. 2019, 27, 117-131. [CrossRef]

14. OECD. Global Competency for an Inclusive World; OECD: Paris, France, 2016.

15. Herberg, M.; Torgersen, G.-E.; Rundmo, T. Competence for the Unforeseen: Social Support and Concurrent Learning as Basic Components of Interaction under Risk. Front. Commun. 2019, 4, 19. [CrossRef] 
16. Torgersen, G.E.; Steiro, T.J. Ledelse, Opplæring og Samhandling i Fleksible Organisasjoner. Om Menneskeliggjøring av Styringssystemer. [Leadership, Training and Collaboration in Flexible Organisations. On the Humanization of Management Systems]; Læringsforlaget: Stjørdal, Trøndelag, 2009.

17. Steiro, T.J.; Torgersen, G.-E. The Terms of Interaction and Concurrent Learning in the Definition of Integrated Operations. In Handbook of Research on Multidisciplinary Approaches to Entrepreneurship, Innovation, and ICTs; Rosendahl, T., Hepsø, V., Eds.; IGI Global: Hershey, PA, USA, 2013; pp. 328-340.

18. Miles, S.A.; Watkins, M.D. The leadership team: Complementary strengths or conflicting agendas? Harv. Bus. Rev. 2007, 85, 186.

19. Torgersen, G.-E.; Steiro, T.J. Defining the Term Samhandling. In Interaction: 'Samhandling' Under Risk. A Step Ahead of the Unforeseen; Torgersen, G.-E., Ed.; Cappelen Damm Akademisk: Oslo, Norway, 2018; pp. 39-54. [CrossRef]

20. Heifetz, R.; Grashow, A.; Linsky, M. Leadership in a (permanent) crisis. Harv. Bus. Rev. 2009, 87, 62-69. [PubMed]

21. Torgersen, G.E. The Idea of a Military Pedagogical Doctrine. In Military Pedagogies. And Why They Matter; Kvernbekk, T., Simpson, H., Peters, M.A., Eds.; Educational Futures Series—Rethinking Theory and Practice; Sense Publishers: Rotterdam, The Netherlands, 2008.

22. Torgersen, G.E.; Firing, K.; Steiro, T. Make the Invisible Enemy Visible: Military Debriefing in the Time of Unforeseen. In Military Psychology Response to Post Pandemic Reconstruction; Rawat, S., Boe, O., Piotrowski, A., Eds.; Rawat Publications: Jaipur, India, 2020; forthcoming.

23. Steiro, T.J.; Firing, K. Coaching and Mentoring in Military Training: An Educational Perspective. In Mentoring og Coaching i et Læringsperspektiv; Karlsdottir, R., Kvalsund, R., Eds.; Tapir Akademisk Forlag: Trondheim, Norway, 2009.

24. Bennis, W.G.; O'Toole, J. How business schools lost their way. Harv. Bus. Rev. 2005, 83, 96. [PubMed]

25. Antonacopoulou, E.P.; Sheaffer, Z. Learning in crisis: Rethinking the relationship between organizational learning and crisis management. J. Manag. Inq. 2014, 23, 5-21. [CrossRef]

26. Berlin, J.H.; Carlström, E.D. Collaboration Exercises: What Do They Contribute?-A Study of Learning and Usefulness. J. Contingencies Crisis Manag. 2015, 23, 11-23. [CrossRef]

27. Torgersen, G.E.; Bergh, J. Forsvarets Pedagogiske Grunnsyn. Med fokus på læring; Forsvarets Skolesenter: Oslo, Norway, 2006.

28. Nyhus, I.; Steiro, T.J.; Torgersen, G.-E. Apprenticeship Learning in Preparation for Meeting the Unforeseen. In Interaction: 'Samhandling' Under Risk. A Step Ahead of the Unforeseen; Torgersen, G.-E., Ed.; Cappelen Damm Akademisk: Oslo, Norway, 2018; pp. 107-126.

29. De Geus, A.P. Planning as Learning. March/April Harv. Bus. Rev. 1988, 88, 70-74. 